\title{
PENINGKATAN KINERJA ORGANISASI MELALUI PERENCANAAN STRATEGI
}

\author{
Widodo \\ Fakultas Ekonomi Unissula Semarang \\ e-mailwidodos3@vahoo.com
}

\begin{abstract}
The purpose of this study was to test empirically the effects of cross-functional integration, communication quality, completeness, commitment, capability, content strategy and organizational performance adaptability. With purposive sampling, respondents to this study is 120 executives from a total of 526 executives of small banks in the Province of Central Java. The data were analyzed using SEM (Structural Equation Model) with the AMOS program. The findings of this study indicate that all hypotheses have been significantly accepted. Thus, the managerial implications of these findings as an effort to improve the quality of organizational performance can be achieved through improving the quality of service content strategy that is built with highly adaptability
\end{abstract}

Keywords: organizational performance, communication quality, completeness, commitment, capability, content strategy.

\begin{abstract}
Abstrak
Tujuan penelitian ini adalah untuk menguji secara empiris efek lintas-fungsional integrasi, kualitas komunikasi, kelengkapan, komitmen, kemampuan, strategi konten dan kemampuan beradaptasi kinerja organisasi. Dengan metode purposive sampling, responden untuk penelitian ini adalah 120 eksekutif dari total 526 eksekutif perbankan kecil di Propinsi Jawa Tengah. Data kemudian dianalisis dengan menggunakan SEM (Structural Equation Model) dengan program AMOS. Temuan penelitian ini menunjukkan bahwa semua hipotesis yang dibangun dapat diterima secara significan. Implikasi manajerial dari temuan ini sebagai upaya meningkatkan kualitas kinerja organisasi dapat di capai melalui meningkatan kualitas pelayanan strategi konten yang dibangun dengan kemampuan adaptasi yang tinggi.
\end{abstract}

Kata kunci: kinerja organisasi, kualitas komunikasi, kelengkapan, komitmen, kemampuan, strategi konten

\section{PENDAHULUAN}

Masalah mendasar di dalam manajemen strategi adalah bagaimana sebuah organisasi perusahaan dapat mencapai kinerja yang superior dan mempertahankan keunggulan bersaing (Teece et al, 1997). Strategi merupakan kunci sukses yang mempengaruhi kinerja organisasi (Bokor and Olson, 1995; dan Ferdinand, 2002a). Hal tersebut karena strategi merupakan rencana keseluruhan yang menjelaskan posisi daya saing suatu perusahaan (Mintzberg, 1990; dan Quinn and Hart, 1993)

Realita menunjukkan bahwa tidak semua pebisnis sukses dengan strategi yang dimiliki. Kondisi tersebut berkaitan dengan kualitas strategi yang dimiliki. Strategi yang berkualitas adalah strategi yang dibangun dengan formulasi, implementasi dan evaluasi strategi yang berkualitas (Menon et al., 1999). Proses pengembangan strategi yangharus berangkat dari keyakinan dasar bahwa strategi harus memiliki isi strategi yang sesuai, dengan proses formulasi yang berkualitas serta kejelasan dan ketegasan implementasi yang akan dilakukan (Varadarajan and Jayachandran, 1999).

Hasil studi mengenai komponen-komponen kualitas perencanaan strategi terdapat 
kontroversi. Hal tersebut mencakup: (1) Kelengkapan kajian mempengaruhi kinerja (Menon et al., 1999). Studi lain, Gima and Murray (2004) menyimpulkan bahwa kelengkapan kajian tidak mempunyai pengaruh pada kinerja;(2) Koordinasi lintas fungsi tidak berpengaruh terhadap kinerja (Menon et al., 1999). Studi lain,Song et al. (2000) berpengaruh terhadap kinerja; dan 3).Komitmen tidak berpengaruh terhadap kinerja (Menon et al., 1999). Namun studi Deery and Iverson (2005) komitmen berpengaruh terhadapkinerja organisasi.

Studi Bokor and Olson (1995) menjelaskan bahwa studi strategi dominan dilakukan pada perusahaan besar, sehingga informasi tentang strategi yang diterapkan perusahaan-perusahaan kecil sangat terbatas. Kondisi tersebut merupakan area studi yang baik karena perusahaan kecil memiliki kontribusi yang tinggi terhadap penciptaan lapangan kerja dan pengembangan ekonomi. Ferry and Messori (2000) menyatakan bahwa bank kecil (Bank Perkreditan Rakyat) mempunyai daya hidup dan kelanggengan usaha bila mampu menciptakan keunggulan yaitu keunggulan dalam hal informasi nasabah dan lingkungan usaha sekitar. Oleh karena itu untuk dapat bersaing secara berhasil bank-bank komunitas berukuran kecil harus menyesuaikan strateginya di dalam industri perbankan yang bersifat sangat dinamis (Silverman and Castaldi, 1998) dan Erdem et al. (2011). Studi ini bertitik tolak dari adanya masalah perbedaan hasil studi (kontroversi) mengenai variabel-variabel kualitas perencanaan serta fenomena industri BPR di Provinsi Jawa Tengah dengan tingkat kredit macet (NPL) tahun 2010 sebesar $11.5 \%$ di atas ketentuan Bank Indonesia 5\%.

\section{KAJIAN PUSTAKA}

\section{Kualitas Konten Strategi}

Studi Bokor and Olson (1995) dan Boyne et al. (2006) menjelaskan bahwa konten strategi berkaitan dengan jenis keputusan strategi. Pendapat lain Ferdinand (2002b) konten strategi adalah menjawab apa yang jadi strategi atau upaya mengkaji secara baik apa wujud strategi yang akan dilakukan. Kapabilitas suatu perencanaan strategi berkaitan dengan konten strategi (Slotegraaf and Dickson, 2004). Konten strategi menjadi pedoman bagi manajer me- lakukan rencana tindakan pada saat lingkungan organisasi mengalami perubahan. Konten strategi yang ditentukan secara rasional akan berpeluang untuk mengurangi intensitas perubahan. Kemudian konten strategi juga dapat mengintegrasikan sumber daya dengan langkah-langkah tindakan khusus, sehingga alokasi sumber daya akan dapat meningkatkan keberhasilan tindakan yang bersangkutan.

Dimensi konten strategi menurut Varadarajan and Jayachandran (1999) mencakup beberapa aspek, yaitu: (1) kompetitif, (2) inovatif, dan (3) berkelanjutan. Studi Luquette (1997) dan Slotegraaf and Dickson (2004) indikasi adanya konten strategi yang berkualitas ditunjukkan dengan: (a) conform, (b) Time, (c) Suite, and (d). Acomodate. Studi Bokor and Olson (1995) menunjukkan bahwa proses strategi dan konten strategi terdapat interaksi. Kemudian proses strategi dan konten strategi yang berkualitas memiliki pengaruh terhadap kinerja organisasi.Walker and Boyne (2006) menjelaskan bahwa kualitas strategy process dan strategy content mempunyai pengaruh terhadap kinerja. Hasil studi lain, Walker and Neil (1997) konten strategi tidak ada pengaruh dengan kinerja organisasi. Mengacu pada studi Bokor and Olson (1995) dan studi Slotegraaf and Dickson (2004) serta Andrews and Boyne (2009), maka hipotesis yang diajukan adalah:

H1: Semakin tinggi kualitas konten strategi, semakin tinggi kinerja organisasi.

\section{Integrasi Lintas Fungsi}

Integrasi lintas fungsi merupakan komponen penting bagi kelangsungan organisasi yang ingin memenangkan persaingan dengan cara mengoptimalkan fungsi-fungsi yang ada dalam perusahaan secara cermat (Kohli and Jaworski, 1990). Studi Song and Dyer (2000) dan Parry, Ferrín, Pilar and Varela (2010) menjelaskan bahwa bahwa indikasi integasi lintas fungsi, yakni: (1) keterlibatan (Level of cross functional involment) berkaitan dengan derajat koordinasi pada tingkat pemasar, Research \& development, produksi dan keuangan yang menganalisis peluang pasar serta potensi pelanggan yang potensial, (2) Kualitas (Quality cross functional informantion) berkaitan dengan ketepatan waktu dan keteapatan informasi pada masing-masing bagian pemasar Research \& development, 
produksi dan keuangan, (3) Harmoni (Harmony of cross functional relations) berkaitan dengan derajat koordinasi pada aspek komunikasi, interaksi dan kerja sama pada pemasar, Research \& development, produksi dan keuangan yang bertanggung jawab dan terjadi kepuasan dalam berinteraksi.

Studi lain Ferdinand (2002a) menyatakan bahwa prasyarat pengembangan strategi yang bermutu harus berangkat dari sebuah proses baku dengan mempertimbangkan berbagai sumber daya dan kapabilitas yang ada dalam organisasi melalui sebuah proses inte grasi lintas fungsi dan lintas bidang. Kondisi tersebut berpeluang mengkaji secara baik apa wujud strategi yang akan dilakukan. artinya terdapat kesesuaian antara konten strategi dengan formulasi yang berkualitas serta kejelasan bagaimana implementasi strategi akan dilakukan. Berdasarkan telaah pustaka tersebut di atas, maka hipotesis yang diajukan adalah:

$\mathrm{H} 2$ : Semakin tinggi derajat integrasi lintas fungsi, semakin tinggi kualitas konten strategi yang dihasilkan

\section{Komunikasi}

Menurut Sengupta et al. (2000) dan Zeffane et al. (2011), kualitas komunikasi merupakan derajat sejauhmana kandungan yang dikomunikasikan diterima dan dipahami oleh pihak lain dalam suatu hubungan. Mutu sebuah komunikasi dapat diartikan sebagai pengembangan komunikasi formal dan informal selama proses strategi dibuat (Miller and Michael, 1998) and Lowry et al. (2009). Studi Menon et al. (1999) dan Sengupta et al. (2000) menjelaskan bahwa indikasi adanya kualitas komunikasi ditunjukkan dengan: (1) Pembuat strategi yang terlibat melakukan interaksi secara terus-menerus selama proses pelaksanaan, (2). Terdapat komunikasi dua arah/umpan balik, (3) Anggota team secara terbuka melakukan komunikasi ketika melaksanakan aktivitas, (4) Selama pelaksanaan terjadi komunikasi secara luas baik yang bersifat formal.

Kualitas komunikasi mempunyai pengaruh positif dan signifikan terhadap proses strategi dan konten strategi (Luquette, 1990 dan Lowry et al. 2009). Hasil studi Michallisin et al. (1997), Johlke and Ferris (2000) dan Goebel et al. (2004) menyimpulkan bahwa kualitas komunikasi berpengaruh terhadap kinerja organisasi. Studi lain, Ulrih and Richard (1997) menjelaskan bahwa frekuensi interaksi akan mempengaruhi kepercayaan pada suatu hubungan. Lebih lanjut dijelaskan bahwa kualitas dan frekuensi komunikasi merupakan faktor yang menentukan secara meyakinkan saling pengertian antara anggota dalam suatu hubungan dalam mencapai tujuan bersama. Hasil studi lain, Menon et al. (1999) menunjukkan bahwa kualitas komunikasi tidak berpengaruh terhadap kinerja organisasi.

Ferdinand (2002b) menyatakan bahwa wujud atau citra sebuah organisasi akan sangat dipengaruhi oleh lingkungan organisasi. Pola transmisi pesan-pesan organisasional yang tercermin dalam praktek-praktek formalisasi dan informasi dan komunikasi. Organisasi yang demikian akan memberikan corak atau mutu sebuah strategi. Berdasarkan telaah pustaka tersebut di atas, maka hipotesis yang diajukan adalah:

H3: Semakin tinggi kualitas komunikasi, semakin tinggi kualitas konten strategi yang dihasilkan

\section{Kelengkapan Kajian}

Menurut Gima and Murray (2004), Forbes (2007) dan Miller (2008), kelengkapan kajian merupakan aktivitas merancang anggota secara menyeluruh dan luas untuk mencari informasi pasar, membuat macam-macam tindakan alternatif, pengujian berbagai penjelasan dan penggunaan kriteria yang spesifik dalam keputusan pengembangan dan implementasi strategi. Studi yang dilakukan Menon et al. (1999) menjelaskan bahwa indikasi adanya kelengkapan kajian yang comprehensiveness tinggi dalam proses pengembangan strategi adalah sebagai berikut: (1) terdapat pengembangan berbagai macam tindakan alternatif untuk mencapai sasaran hasil diharapkan, (2) terdapat alternatif tindakan untuk memanfaatkan peluang, dan (3) terdapat sejumlah alternatif yang dihasilkan derajat analisis yang mendalam.

Hasil studi Menon et al. (1999) menjelaskan bahwa comprehensiveness baik secara teoritis maupun pengujian empiris dapat mempengaruhi kinerja. Studi lain, Gima and Murray (2004) menyimpulkan bahwa kelengkapan kajian (comprehensiveness) tidak mempunyai pengaruh pada kinerja. Proses baku 
sebuah prasyarat pengembangan strategi adalah analisis situasi, kelengkapan kajian kapabilitas, sumber daya, integrasi lintas fungsi dan lintas bidang serta komitmen akan berpotensi untuk menjadi strategi yang bermutu, kelengkapan kajian merupakan kunci dari sebuah kualitas strategi (Ferdinand, 2002a). Oleh karena itu dengan proses yang comprehensiveness pada proses strategi dapat meningkatkan kualitas strategi (Menon et al., 1999). Kualitas strategi mencakup aspek konten strategi, implementasi dan evaluasi strategi (Varadarajan and Jayachandran, 1999). Berdasarkan telaah pustaka di atas, maka hipotesis yang diajukan adalah:

H4: Semakin tinggi kelengkapan kajian proses pengembangan strategi, semakin tinggi kualitas konten strategi yang dihasilkan

\section{Adaptabilitas}

Menurut Denison and Mishra (1995) adaptabilitas mendasarkan pada kemampuan menyesuaikan dengan perubahan lingkungan organisasi. Adaptabilitas sebuah organisasi harus mengembangkan norma-norma dan keyakinankeyakinan yang bersifat menunjang kemampuan untuk menerima dan kemudian menafsirkan berbagai sinyal yang berasal dari lingkungan dan menjabarkan ke dalam perubahan kognitif dan perilaku. Kesuksesan organisasi tergantung dari adaptasi internal pada lingkungan (Leonidou, 2011).

Studi yang dilakukan oleh Dess et al. (1997) menjelaskan bahwa organisasi yang memiliki kemampuan adaptasi dengan lingkungan ditunjukkan dengan indikasi meliputi: (1) organisasi secara terus menerus menyesuaikan perubahan dengan membuat strategi sesuai dengan umpan balik yang didasarkan pasarnya, (2) proses perencanaan produk dan bisnis menyesuaikan atau melibatkan pelanggan, suplies dan penyedia dana, dan (3) organisasi dengan cepat melakukan penyesuaian dengan perubahan lingkungan.

Studi yang dilakukan Noel and Banerjee (1999) menjelaskan bahwa adaptabilitas mempunyai pengaruh yang positif dan siginifikan terhadap kinerja organisasi. Studi lain yang dilakukan Leonidou (2011) dan Deborah and Damanpour (2000) menunjukkan bahwa organisasi yang memiliki kemampuan beradaptasi dengan lingkungan akan memiliki kinerja yang tinggi. Mempertimbangkan studi empiris dan telaah pustaka di atas, maka hipotesis yang diajukan adalah:

H5: Semakin tinggi kemampuan derajat adaptablitas dengan lingkungan organisasi, semakin tinggi kinerja organisasi.

Kemampuan untuk belajar dan beradaptasi merupakan bagian dari kompetensi manajemen. Organisasi yang memberi perhatian dan kemampuan belajar dan beradaptasi akan memiliki kompetensi strategi yang baik karena memberi warna yang bermutu pada strategi yang dikembangkan (Pit and Kannemeyer, 2000). Selanjutnya mereka menjelaskan bahwa organisasi yang memiliki kemauan untuk beradaptasi, instrumen-instrumen kunci kebijakan akan memiliki kinerja yang baik. Informasi mengenai lingkungan dicari untuk memberikan ruang gerak stratejik yang luas dalam pengembangan berbagai strategi yang dilakukan untuk tetap memenangkan persaingan yang ketat. Oleh karena itu manajemen yang memiliki orientasi kuat pada upaya mencari dan mengakses informasi mengenai peluang-peluang, baik yang dapat dimasuki maupun yang dikenali akan menghasilkan strategi yang berkualitas. Dimensi kualitas strategi mencakup: (1) conten, (2) formulation process, dan (3) implementation (Varadarajan and Jayachandran, 1999)). Berdasarkan telah pustaka di atas, maka hipotesis yang diajukan adalah:

H6: Semakin tinggi adaptabilitas organisasi, semakin tinggi kualitas konten strategi yang dihasilkan

\section{Komitmen}

Bhattacharya et al. (2005) memberikan pengertian bahwa komitmen karyawan merupakan suatu bentuk identifikasi, loyalitas dan keterlibatan yang diekspresikan oleh karyawan terhadap organisasi atau unit. Indikasi adanya komitmen yang tinggi adalah sebagai berikut: (1) Ada pihak-pihak yang berkepentingan memiliki hasrat untuk memastikan melaksanakan suatu keputusan, (2) semua pihak memiliki kemauan untuk memberikan pengorbanan, (3) semua pihak memiliki ikatan emosional, dan (4) semua pihak memiliki kesamaan kepentingar(Menon et al., 1 999).

Studi empiris tentang komitmen menjelaskan bahwa tidak adanya komitmen umum- 
nya berkaitan dengan "turn over karyawan" dengan intensitas tinggi, ketidak puasan, perilaku sumber daya manusia cenderung menutup diri dan rendahnya kinerja (Cohen, 1993). Deery and Iverson (2005) menyimpulkan bahwa komitmen berpengaruh pada kinerja. Studi lain dilakukan oleh Judge and Dooley (2000) menjelaskan bahwa konsensus mempengaruhi komitmen dan komitmen mempengaruhi efektifitas implementasi strategi. Studi empiris Locander and Jaramillo (2006) menyimpulkan: (1) Komitmen organisasi dipengaruhi oleh kepercayaan supervisor, (2) kepuasan pekerjaan dan ethical climat, dan (3) komitmen berpengaruh pada turnover intention. Namun demikian studi Menon et al.(1999), komitmen tidak berpengaruh pada kinerja. Berdasarkan telaah pustaka tersebut, maka hipotesis yang diajukan adalah:

H7: Semakin tinggi komitmen pada konsensus, semakin tinggi kemampuan adaptabilitas organisasi pada perubahan lingkungan.

\section{Kapabilitas}

Grant (1991), Han et al. (1998) dan Kaleka (2011) menjelaskan bahwa kapabilitas perusahaan merupakan landasan untuk strategi jangka panjang. Assets dan skill atau asset dan kompetensi merupakan instrumen strategic yang paling dasar untuk menghasilkan daya saing (Aaker, 1989).

Quin and Hart (1993); dan Mithas et al.

(2011) mengemukakan bahwa karyawan yang lebih kapabel, lebih berpengalaman dan lebih berpengetahuan memiliki kemampuan merancang bisnis sesuai dengan tuntutan situasi pekerjaan. Hal tersebut terjadi karena karyawan tersebut akan mampu mengurangi ketidakpastian organisasional dan meningkatkan kemampuan organisasi beradaptasi dengan lingkungan dan kondisi baru. Berdasarkan telaah pustaka tersebut, maka hipotesis yang diajukan adalah:

H8: Semakin tinggi kapabilitas organisasi, semakin tinggi tingkat adaptabilitas organisasi dengan perubahan lingkungan.

\section{Model Empirik}

Berdasarkan telaah pustaka maka model empirik penelitian kualitas perencanaan strategi ini, nampak pada Gambar 1.

\section{METODE PENELITIAN}

\section{Disain Penelitian}

Studi ini di awali dengan kegiatan exploraratory research, yang merupakan kegiatan riset awal untuk mencari dan membatasi permasalahan penelitian agar bersifat applicable dan researchable (Zigmund, 2003). Penelitian ini bertujuan untuk memperbaiki teori-teori yang berkaitan dengan penyelesaian masalah yang terjadi dalam organisasi. Oleh karena itu jenis penelitian menggunakan jenis penelitian fundamental research (Sekaran, 2003).

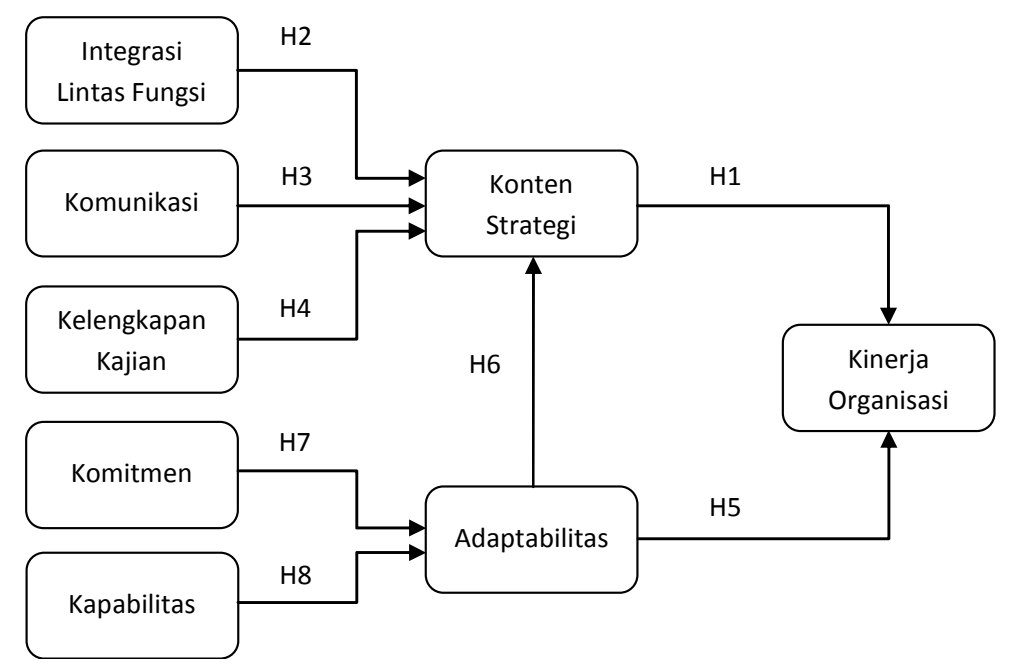

Gambar 1: Model penelitian empirik perencanaan strategi 


\section{Sumber dan Teknik Pengumpulan Data}

Sumber data pada studi ini mencakup data primer dan data sekunder. Data primer merupakan data yang diperoleh langsung dari responden yakni manajer BPR di Provinsi Jawa Tengah. Data ini diambil berdasarkan kuesioner yang dibagikan kepada responden. Adapun data primer dalam penelitian ini adalah tanggapan responden terhadap variabel penelitian. Data sekunder adalah data yang telah diolah oleh orang atau lembaga lain dan telah dipublikasikan. Data tersebut diperoleh dari Bank Indonesia, Badan Pusat Statistik (BPS),
Perhimpunan Bank Perkreditan Rakyat Indonesia (Perbarindo) maupun dari literatur-literatur yang berkaitan dengan studi ini.

Kemudian teknik pengumpulan data yang dilakukan dalam penelitian ini dengan menggunakan angket, yakni suatu daftar yang berisi sejumlah pertanyaan yang diberikan kepada manajer BPR di Provinsi Jawa Tengah yang berjumlah 120 responden.

\section{Variabel dan Indikator}

Variabel dan indikator penelitian dapat disajikan seperti pada tabel 1 .

Tabel 1: Variabel dan Indikator Penelitian

\begin{tabular}{|c|c|c|c|}
\hline No & Variabel & Indikator & Sumber \\
\hline 1 & $\begin{array}{l}\text { Integrasi Lintas Fungsi } \\
\text { Koordinasi antar fungsional dalam organisasi }\end{array}$ & $\begin{array}{l}\text { - Terdapat koordinasi secara baik } \\
\text { - Memiliki wakil-wakil yang } \\
\text { memadai } \\
\text { - Kualitas koordinasi } \\
\text { - Koordinasi harmonis }\end{array}$ & Menon et al. (1999) \\
\hline 2 & $\begin{array}{l}\text { Komunikasi } \\
\text { Derajat kandungan yang dikomunikasikan } \\
\text { diterima dan dipahami oleh pihak lain dalam } \\
\text { suatu hubungan }\end{array}$ & $\begin{array}{l}\text { - Interaksi yang kontinu } \\
\text { - Transparansi } \\
\text { - Umpan balik } \\
\text { - Komunikasi Formal }\end{array}$ & Menon et al. (1999) \\
\hline 3 & $\begin{array}{l}\text { Kelengkapan Kajian } \\
\text { Alternatip-alternatip secara lebih mendalam } \\
\text { dan menciptakan keinginan untuk menemukan } \\
\text { cara-cara yang lebih baru dan lebih baik untuk } \\
\text { melakukan berbagai tugas. }\end{array}$ & $\begin{array}{l}\text { - Pengembangan Alternatif } \\
\text { tindakan } \\
\text { - Alternatif pemanfaatan peluang } \\
\text { - Alternatif hasil dengan analisis } \\
\text { mendalam }\end{array}$ & $\begin{array}{l}\text { Gima \& Murray } \\
\text { (2004); Menon et } \\
\text { al. (1999) }\end{array}$ \\
\hline 4 & $\begin{array}{l}\text { Komitmen } \\
\text { Komitmen pada konsensus }\end{array}$ & $\begin{array}{l}\text { - Memiliki hasrat } \\
\text { - Memiliki kemauan } \\
\text { - Memiliki ikatan emosioanal } \\
\text { - Kesamaan kepentingan }\end{array}$ & $\begin{array}{l}\text { Menon et al. } \\
\text { (1999); } \\
\text { Cook J, Wall T. } \\
\text { (1980) }\end{array}$ \\
\hline 5 & $\begin{array}{l}\text { Kapabilitas } \\
\text { Kapabilitas yang dimiliki SDM untuk } \\
\text { melaksanakan pekerjaan yang dapat } \\
\text { memberikan nilai bagai organisasi. }\end{array}$ & $\begin{array}{l}\text { - Pengetahuan } \\
\text { - Ketrampilan } \\
\text { - Pengalaman }\end{array}$ & $\begin{array}{l}\text { Kulkarni (2010); } \\
\text { Ferdinand (2003) }\end{array}$ \\
\hline 6 & $\begin{array}{l}\text { Kualitas Konten Strategi } \\
\text { Bentuk atau wujud strategi yang dilakukan. }\end{array}$ & $\begin{array}{l}\text { - Kesesuaian } \\
\text { - Rentang Waktu yang jelas } \\
\text { - Berkelanjutan } \\
\text { - Akomodatif }\end{array}$ & $\begin{array}{l}\text { Luquette (1990); } \\
\text { Slotegraaf and } \\
\text { Dikson (2004) }\end{array}$ \\
\hline 7 & $\begin{array}{l}\text { Adaptabilitas } \\
\text { Kemampuan untuk melakukan perubahan } \\
\text { internal sebagai respon terhadap lingkungan }\end{array}$ & $\begin{array}{l}\text { - Kontinuitas adaptasi } \\
\text { - Menyesuaikan stakeholder } \\
\text { - Kecepatan penyesuaian }\end{array}$ & $\begin{array}{l}\text { Dess, Lumpin and } \\
\text { Covin (1997) }\end{array}$ \\
\hline 8 & $\begin{array}{l}\text { Kinerja Organisasi } \\
\text { Merupakan hasil yang telah dicapai dari yang } \\
\text { telah dilakukan, dikerjakan manajer BPR } \\
\text { dalam melaksanakan kerja atau tugas yang } \\
\text { dibebankan oleh organisasi. }\end{array}$ & $\begin{array}{l}\text { - Profitability } \\
\text { - Market share } \\
\text { - Efisiensi } \\
\text { - Posisi Pasar }\end{array}$ & $\begin{array}{l}\text { Walker and Boyne } \\
\text { (2004); Walker and } \\
\text { Neil (1997) }\end{array}$ \\
\hline
\end{tabular}




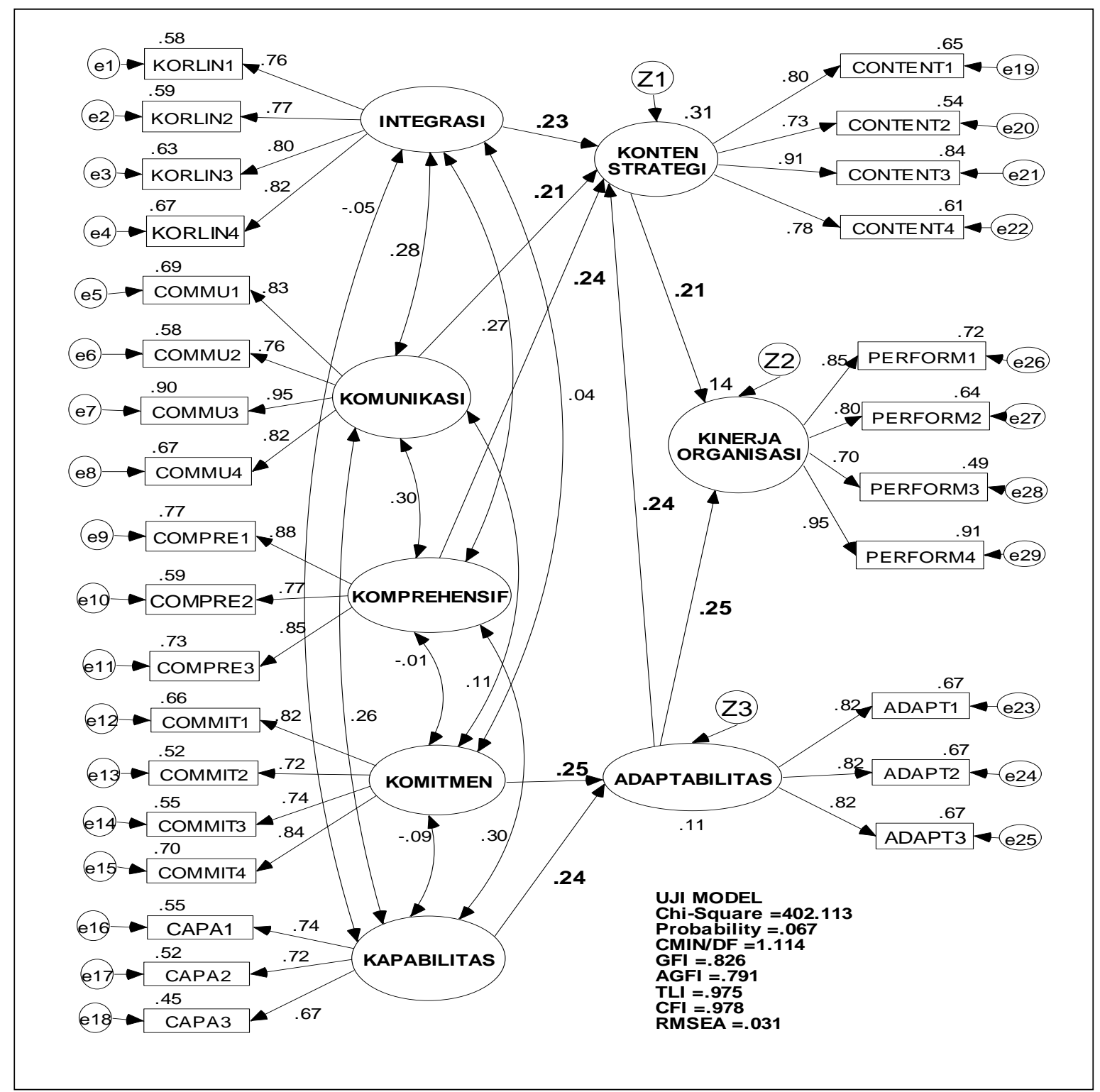

Gambar 2: Full Model Perencanaan Strategi

\section{Populasi dan Sampel}

Populasi adalah kumpulan dari individu dengan kualitas serta ciri-ciri yang telah ditetapkan. Populasi dalam penelitian ini meliputi seluruh pimpinan Bank Perkreditan Rakyat (BPR) di Propinsi Jawa Tengah yang berjumlah 525 . Studi ini menggunakan model estimasi Maximum Likelihood (ML) besarnya sampel 100-200 (Gozali, 2001; Hair et al., 2006). Responden studi ini terdiri dari pimpinan Bank Perkreditan Rakyat (BPR) di Provinsi Jawa Tengah, hal tersebut karena mencerminkan orientasi strategi bisnis Bank Perkreditan Rakyat (BPR) dan pimpinan Bank Perkreditan
Rakyat (BPR) dapat mewakili (representase) organisasi BPR yang ada.

Dengan metode Purposive Sampling, maka sampel yang diambil dengan mempertimbangkan karakteristik populasi, yaitu: (a). Pengalaman operasional minimal 5 tahun, (b) representase dari wilayah kerja Kantor Bank Indonesia Semarang, Kantor Bank Indonesia Surakarta dan Kantor Bank Indonesia Purwokerto. Oleh karena itu jumlah sampel tersebut terdistribusi pada 75 pimpinan BPR Wilayah kerja Bank Indonesia Semarang, 29 pimpinan BPR Wilayah kerja Bank Indonesia Surakarta dan 16 BPR pimpinan Wilayah kerja Bank Indonesia Purwokerto. 


\section{Teknik Analisis}

Untuk menganalisis data dalam penelitian ini digunakan The Structural Equation Modelling (SEM) dari paket software AMOS 4.0.Model ini merupakan sekumpulan teknik-teknik statistik yang memungkinkan pengujian sebuah rangkaian hubungan relatif rumit (Ferdinand, 2000).

\section{HASIL ANALISIS}

Setelah model dianalisis melalui faktor konfirmatori, maka masing-masing indikator dalam model yang fit tersebut dapat digunakan untuk mendefinisikan konstruk laten, sehingga full model Structural Equation Model (SEM) dapat dianalisis. Hasil pengolahannya dapat dilihat pada Gambar 2 di atas. Pada gambar tersebut menunjukkan bahwa model ini sesuai dengan data atau fit terhadap data yang digunakan dalam penelitian. Hal tersebut ditunjukkan dengan $\mathrm{Chi}$ Square, Probability, CMIN/DF, TLI berada dalam rentang nilai yang diharapkan meskipun GFI dan AGFI diterima secara marjinal.

\section{Pengujian Hipotesis}

Parameter estimasi hubungan kausalitas antara konstruk yang dihipotesiskan dianalisis dengan menggunakan kriteria Critical ratio yang identik dengan uji-t dalam analisis regresi menunjukkan hasil seperti yang disajikan Tabel 2 di bawah. Tabel tersebut menunjukkan bahwa parameter estimasi menunjukkan hasil yang signifikan dengan nilai $\mathrm{CR} \geq \pm 2,00$ dengan taraf signifikan sebesar $0,05(5 \%)$, dengan demikian 7 hipotesis yang diajukan diterima.

\section{PEMBAHASAN}

Diterimanya hipotesis 1 menunjukkan bahwa kualitas konten strategi berpengaruh terhadap kinerja organisasi. Hasil tersebut mengindikasikan bahwa untuk meningkatkan kinerja organi- sasi dibangun oleh kualitas konten strategi. Berdasarkan deskripsi jawaban responden pada variabel kualitas konten strategi yang diindikasikan oleh empat dimensi telah dibuat dengan dengan baik, walaupun belum mencapai kondisi yang optimal. Secara keseluruhan rumusan strategi yang ada di BPR terdapat kesesuaian atau keselarasan dengan sumber daya yang dimiliki. Semua rumusan strategi kami memiliki rentang waktu yang jelas. Rumusan strategi tidak hanya berorientasi jangka pendek, namun juga berorientasi jangka panjang atau berkelanjutan. Semua rumusan strategi dapat mengakomodasi kepentingan berbagai pihak.

Selanjutnya kualitas konten strategi yang tercipta dari empat dimensi tersebut akan mendorong peningkatan kinerja organisasi. Kinerja organisasi yang diindikasikan oleh empat dimensi sesuai dengan analisis deskripsi jawaban responden menunjukkan hasil yang belum optimal (Tabel 1). Hal tersebut menunjukkan bahwa kinerja organisasi yang cukup tinggi walaupun belum sesuai dengan yang diharapkan. Kinerja organisasi yang baik ditunjukan dengan rata-rata profitability selama tiga tahun terakhir berada di atas rata-rata industri. Rata-rata market share selama tiga tahun terakhir berada di atas rata-rata industri. Selama tiga tahun terakhir dapat meningkatkan efisiensi di atas rata-rata industri. Selama tiga tahun terakhir BPR posisi pasar berada di atas rata-rata industri. Walaupun hal tersebut belum terlaksana sesuai harapan, Peningkatan kinerja organisasi dapat tercapai dengan meningkatkan konten strategi. Hasil penelitian ini mendukung secara empirik Bokor and Olson (1995) dan Al Ma'ani et al. (2010) menunjukkan bahwa proses strategi dan konten strategi terdapat interaksi. Kemudian proses strategi dan konten strategi yang berkualitas memiliki pengaruh terhadap kinerja organisasi.

Tabel 2: Regresion Wight

\begin{tabular}{lclccccc}
\hline \multicolumn{2}{c}{ Hubungan } & Stand.Estim & Estimate & S.E. & C.R. & Prob \\
\hline Adaptabilitas & $\leftarrow$ & Komitmen & 0.253 & 0.293 & 0.121 & 2.422 & 0.015 \\
Adaptabilitas & $\leftarrow$ & Kapabilitas & 0.244 & 0.292 & 0.132 & 2.210 & 0.027 \\
Konten_Strategi & $\leftarrow$ & Integrasi & 0.232 & 0.249 & 0.106 & 2.359 & 0.018 \\
Konten_Strategi & $\leftarrow$ & Komunikasi & 0.206 & 0.213 & 0.099 & 2.167 & 0.030 \\
Konten_Strategi & $\leftarrow$ & Komprehensif & 0.238 & 0.226 & 0.093 & 2.422 & 0.015 \\
Konten_Strategi & $\leftarrow$ & Adaptabilitas & 0.242 & 0.263 & 0.101 & 2.608 & 0.009 \\
Kinerja_Organisasi & $\leftarrow$ & Adaptabilitas & 0.248 & 0.260 & 0.108 & 2.411 & 0.016 \\
Kinerja_Organisasi & $\leftarrow$ & Konten_Strategi & 0.213 & 0.205 & 0.096 & 2.130 & 0.033 \\
\hline
\end{tabular}


Hipotesis 2 yakni semakin tinggi derajat integrasi lintas fungsi, semakin tinggi kualitas konten strategi yang dihasilkan, didukung oleh data empiris.Hasil tersebut mengindikasikan bahwa untuk meningkatkan kualitas konten strategi dibangun oleh integrasi lintas fungsi. Berdasarkan deskripsi jawaban responden pada variabel integrasi lintas fungsi yang diindikasikan oleh empat dimensi telah dilaksanakan dengan dengan baik, walaupun belum mencapai kondisi yang optimal. Dalam proses perencanaan strategi terdapat koordinasi secara baik dalam hal aktivitas-aktivitas setiap anggota kelompok. Tim perencana strategi bertanggung jawab dan memiliki wakil-wakil yang memadai dari bagian-bagian lain. Dalam proses perencanaan strategi terdapat koordinasi yang berkualitas (ketepatan waktu dan ketepatan informasi) pada masing-masing bagian. Dalam proses perencanaan strategi terdapat koordinasi yang harmonis (komunikasi, interaksi dan kerja sama) yang baik pada masingmasing bagian.

Selanjutnya integrasi lintas fungsi yang tercipta dari empat dimensi tersebut akan mendorong meningkatkan kualitas konten strategi. Kualitas konten strategi yang dindikasikan oleh empat dimensi sesuai dengan analisis deskripsi jawaban responden menunjukkan hasil yang belum optimal. Hal tersebut menunjukkan bahwa secara keseluruhan rumusan strategi yang ada di BPR terdapat kesesuaian atau keselarasan dengan sumber daya yang dimiliki. Semua rumusan strategi memiliki rentang waktu yang jelas. Rumusan strategi di BPR tidak hanya berorientasi jangka pendek, namun juga berorientasi jangka panjang atau berkelanjutan. Semua rumusan strategi dapat mengakomodasi kepentingan berbagai pihak. Walaupun hal tersebut belum terlaksana sesuai harapan, kualitas konten strategi dapat tercapai dengan meningkatkan integrasi lintas fungsi. Hasil penelitian ini mendukung secara empirik studi Weiss and Hoffer (2004). Oleh karena itu integrasi lintas fungsi harus dilakukan dalam rangka untuk meningkatkan kualitas konten strategi.

Diterimanya hipotesis 3 yang menunjukkan bahwa kualitas komunikasi berpengaruh kualitas konten strategi. Hasil tersebut mengindikasikan bahwa untuk meningkatkan kualitas konten strategi dibangun oleh kualitas komunikasi. Berdasarkan deskripsi jawaban responden pada variabel kualitas komunikasi yang diindikasikan oleh empat dimensi telah dilaksanakan dengan baik, walaupun belum mencapai kondisi yang optimal. Selama proses perencanaan strategi anggota yang terlibat melakukan interaksi secara terus-menerus. Dalam proses perencana strategi anggota tim dapat melakukan komunikasi secara terbuka. Selama proses perencanaan strategi anggota yang terlibat terdapat komunikasi dua arah (umpan balik). Selama proses perencanaan strategi terdapat komunikasi formal (aliran komunikasi yang terstruktur, terencana dan rutin). Selanjutnya kualitas komunikasi yang tercipta dari empat dimensi tersebut akan mendorong meningkatkan kualitas konten strategi. Kualitas konten strategi yang dindikasikan oleh empat dimensi sesuai dengan analisis deskripsi jawaban responden menunjukkan hasil yang belum optimal. Hal tersebut menunjukkan bahwa secara keseluruhan rumusan strategi yang ada di BPR terdapat kesesuaian atau keselarasan dengan sumber daya yang dimiliki. Semua rumusan strategi memiliki rentang waktu yang jelas. Rumusan strategi di BPR tidak hanya berorientasi jangka pendek, namun juga berorientasi jangka panjang atau berkelanjutan. Semua rumusan strategi dapat mengakomodasi kepentingan berbagai pihak. Walaupun hal tersebut belum terlaksana sesuai harapan, kualitas konten strategi dapat tercapai dengan meningkatkan kualitas komunikasi.Hasil penelitian ini mendukung secara empirik studi Weiss and Hoffer (2004) dan Thomas et al. (2009). Oleh karena itu kualitas komunikasi harus dilakukan dalam rangka untuk meningkatkan kualitas konten strategi.

Diterimanya hipotesis 4 yang menunjukkan bahwa kelengkapan kajian berpengaruh kualitas konten strategi. Hasil tersebut mengindikasikan bahwa untuk meningkatkan kualitas konten strategi dibangun oleh kelengkapan kajian. Berdasarkan deskripsi jawaban responden pada variabel kualitas kelengkapan kajian yang diindikasikan oleh tiga dimensi telah dilaksanakan dengan dengan baik, walaupun belum mencapai kondisi yang optimal. Perencanaan strategi organisasi terdapat pengembangan berbagai tindakan alternatif untuk mencapai sasaran hasil diharapkan. Pada perencanaan strategi terdapat tindakan alternatif untuk memanfaatkan peluang. Pada perencanaan strategi terdapat sejumlah alternatif yang 
dihasilkan dengan derajat analisis yang mendalam. Selanjutnya kelangkapan kajian (comprehensiveness) yang tercipta dari empat dimensi tersebut akan mendorong meningkatkan kualitas konten strategi. Kualitas konten strategi yang dindikasikan oleh empat dimensi sesuai dengan analisis deskripsi jawaban responden menunjukkan hasil yang belum optimal. Hal tersebut menunjukkan bahwa secara keseluruhan rumusan strategi yang ada di BPR terdapat kesesuaian atau keselarasan dengan sumber daya yang dimiliki. Semua rumusan strategi memiliki rentang waktu yang jelas. Rumusan strategi di BPR tidak hanya berorientasi jangka pendek, namun juga berorientasi jangka panjang atau berkelanjutan. Semua rumusan strategi dapat mengakomodasi kepentingan berbagai pihak. Walaupun hal tersebut belum terlaksana sesuai harapan, kualitas konten strategi dapat tercapai dengan meningkatkan kelngkapan kajian (comprehensiveness). Hasil penelitian ini mendukung studi Ferdinand (2002a). Oleh karena itu kelengkapan kajian harus dilakukan dalam rangka untuk meningkatkan kualitas konten strategi.

Diterimanya hipotesis 5 yang menunjukkan bahwa adaptabilitas berpengaruh terhadap kinerja organisasi. Hasil tersebut mengindikasikan bahwa untuk meningkatkan kinerja organisasi dibangun oleh adaptabilitas. Berdasarkan deskripsi jawaban responden pada variabel adaptabilitas yang diindikasikan oleh tiga dimensi telah dilaksanakan dengan dengan baik, walaupun belum mencapai kondisi yang optimal. Organisasi secara terus menerus menyesuaikan perubahan dengan membuat strategi sesuai dengan umpan balik yang berdasarkan pasarnya. Pada perencanaan produk dan bisnis menyesuaikan dengan stakeholder. Keputusan rencana strategi dengan cepat menyesuaikan perubahan yang terjadi. Selanjutnya adaptabilitas yang tercipta dari tiga dimensi tersebut akan mendorong peningkatan kinerja organisasi. Kinerja organisasi yang diindikasikan oleh empat dimensi sesuai dengan analisis deskripsi jawaban responden menunjukkan hasil yang belum optimal. Hal tersebut menunjukkan bahwa kinerja organisasi yang baik walaupun belum sesuai dengan yang diharapkan. Kinerja organisasi yang baik ditunjukan dengan rata-rata profitability selama tiga tahun terakhir berada di atas rata-rata industri. Rata-rata market share selama tiga tahun terakhir berada di atas rata-rata industri. Selama tiga tahun terakhir dapat meningkatkan efisiensi di atas rata-rata industri. Selama tiga tahun terakhir BPR posisi pasar berada di atas rata-rata industri. Walaupun hal tersebut belum terlaksana sesuai harapan, peningkatan kinerja organisasi dapat tercapai dengan meningkatkan kemampuan adaptasi. Hasil penelitian ini mendukung secara empirik studi Leonidou (2011), Troy et al. (2008) dan Deborah (2000). Oleh karena itu adaptabilitas harus dilakukan dalam rangka untuk meningkatkan kinerja organisasi.

Diterimanya hipotesis 6 yang menunjukkan bahwa adaptabilitas berpengaruh terhadap kualitas konten strategi. Adaptabilitas kemampuan menyesuaikan dengan perubahan lingkungan organisasi. Hasil tersebut mengindikasikan bahwa untuk meningkatkan kualitas konten strategi dibangun oleh adaptabilitas. Berdasarkan deskripsi jawaban responden pada variabel adaptabilitas yang diindikasikan oleh tiga dimensi telah dilaksanakan dengan baik, walaupun belum mencapai kondisi yang optimal. Organisasi secara terus menerus menyesuaikan perubahan dengan membuat strategi sesuai dengan umpan balik yang berdasarkan pasarnya. Pada perencanaan produk dan bisnis menyesuaikan dengan stakeholder. Keputusan rencana strategi dengan cepat menyesuaikan perubahan yang terjadi.

Selanjutnya adaptabilitas yang tercipta dari tiga dimensi tersebut akan mendorong meningkatkan kualitas konten strategi. Kualitas konten strategi yang diindikasikan oleh empat dimensi sesuai dengan analisis deskripsi jawaban responden menunjukkan hasil yang belum optimal. Hal tersebut menunjukkan bahwa secara keseluruhan rumusan strategi yang ada di BPR terdapat kesesuaian atau keselarasan dengan sumber daya yang dimiliki. Semua rumusan strategi memiliki rentang waktu yang jelas. Rumusan strategi di BPR tidak hanya berorientasi jangka pendek, namun juga berorientasi jangka panjang atau berkelanjutan. Semua rumusan strategi dapat mengakomodasi kepentingan berbagai pihak. Walaupun hal tersebut belum terlaksana sesuai harapan, kualitas konten strategi dapat tercapai dengan meningkatkan adaptabilitas.Hasil penelitian ini mendukung studi (Pit dan Kannemeyer, 2000) dan Parry et al. (2010). Oleh karena itu adapta- 
bilitas harus dilakukan dalam rangka untuk meningkatkan kualitas konten strategi.

Diterimanya hipotesis 7 yang menunjukkan bahwa komitmen pada konsensus berpengaruh terhadap adaptabilitas. Hasil tersebut mengindikasikan bahwa untuk meningkatkan adaptabilitas dibangun oleh komitmen pada konsensus. Berdasarkan deskripsi jawaban responden pada variabel komitmen pada konsensus yang diindikasikan oleh empat dimensi telah dilaksanakan dengan baik, walaupun belum mencapai kondisi yang optimal. Berbagai pihak yang berkepentingan memiliki hasrat untuk merencanakan strategi. Berbagai pihak yang berkepentingan memiliki kemauan untuk memberikan pengorbanan pada proses perencanaan strategi. Berbagai pihak yang berkepentingan memiliki ikatan emosional pada proses perencanaan strategi. Berbagai pihak yang berkepentingan memiliki kesamaan kepentingan dalam proses perencanaan strategi. Selanjutnya komitmen pada konsensus yang tercipta dari empat dimensi tersebut akan mendorong meningkatkan adaptabilitas yang diindikasikan oleh tiga dimensi sesuai dengan analisis deskripsi jawaban responden menunjukkan hasil yang belum optimal. Organisasi secara terus menerus menyesuaikan perubahan dengan membuat strategi sesuai dengan umpan balik yang berdasarkan pasarnya. Pada perencanaan produk dan bisnis menyesuaikan dengan stakeholder. Keputusan rencana strategi dengan cepat menyesuaikan perubahan yang terjadi, walaupun hal tersebut belum terlaksana sesuai harapan. Kemampuan adaptabilitas organisasi dapat tercapai dengan meningkatkan komitmen pada konsensus. Hasil penelitian ini mendukung studi Mowday (1981), Berberoglu et al. (2011) dan Leonidou (2011). Oleh karena itu komitmen pada konsensus harus dilakukan dalam rangka untuk meningkatkan adaptabilitas.

Diterimanya hipotesis 8 yang menunjukkan bahwa kapabilitas berpengaruh terhadap adaptabilitas. Hasil tersebut mengindikasikan bahwa untuk meningkatkan adaptabilitas dibangun oleh kapabilitas. Berdasarkan deskripsi jawaban responden pada variabel kapabilitas yang diindikasikan oleh tiga dimensi telah dibangun dengan dengan baik, walaupun belum mencapai kondisi yang optimal. Tim anggota perencana strategi memiliki pengetahuan yang memadai. Tim anggota perencana strategi memiliki ketrampilan yang memadai. Tim ang- gota perencana strategi memiliki pengalaman yang memadai.Selanjutnya kapabilitas yang tercipta dari tiga dimensi tersebut akan mendorong meningkatkan adaptabilitas. adaptabilitas yang dindikasikan oleh tiga dimensi sesuai dengan analisis deskripsi jawaban responden menunjukkan hasil yang belum optimal. Organisasi secara terus menerus menyesuaikan perubahan dengan membuat strategi sesuai dengan umpan balik yang berdasarkan pasarnya Pada perencanaan produk dan bisnis menyesuaikan dengan stakeholder. Keputusan rencana strategi dengan cepat menyesuaikan perubahan yang terjadi. Walaupun hal tersebut belum terlaksana sesuai harapan, kemampuan adaptabilitas organisasi dapat tercapai dengan meningkatkan kapabilitas. Hasil penelitian ini mendukung studi Quin and Hart (1993). Oleh karena itu kapabilitas harus ditingkatkan dalam rangka untuk meningkatkan adaptabilitas.

Berdasarkan hipotesis-hipotesis yang telah dikembangkan dalam studi ini, maka masalah penelitian yang telah diajukan dapat dijustifikasi melalui pengujian Structural Equation Modeling (SEM), telah dikonsepkan melalui penelitian ini bahwa hubungan antara variabel-variabel yang mempengaruhi dan dipengaruhi dalam model peningkatan kinerja organisasi melalui perencanaan strategi, dapat disimpulkan: Pertama, langkah-langkah dalam upaya meningkatkan kinerja organisasi dapat dicapai melalui kualitas konten strategi dengan memprioritaskan konten strategi yakni berkelanjutan atau konten strategi berorientasi jangka panjang, kemudian terdapat kesesuaian sumber daya, dapat mengakomodasi kepentingan berbagai pihak dan memiliki rentang waktu yang. Konten strategi dibangun oleh adaptabilitas dengan memprioritaskan kecepatan menyesuaikan perubahan, kemudian terdapat kontinuitas adaptasi dan berdapatasi dengan kepentingan stakeholder; Kedua, langkah-langkah dalam upaya meningkatkan kinerja organisasi dapat dicapai melalui peningkatan kualitas konten strategi; Ketiga, langkah-langkah dalam upaya meningkatkan kinerja organisasi dapat dicapai melalui adanya kelengkapan kajian (komprehensif). Kemudian kondisi tersebut akan meningkatkan kualitas konten strategi; Keempat, langkah-langkah dalam upaya meningkatkan kinerja organisasi dapat dicapai melalui konten strategi yang dibangun oleh integrasi lintas fungsi; Kelima, 
langkah-langkah dalam upaya meningkatkan kinerja organisasi dapat dicapai melalui peningkatan adaptabilitas organisasi yang dibangun oleh kapabilitas; Keenam, langkahlangkah dalam upaya meningkatkan kinerja organisasi dapat dicapai melalui adanya peningkatan adaptabilitas organisasi yang dibangun oleh komitmen pada konsensus. Terakhir, langkah-langkah dalam upaya meningkatkan kinerja organisasi dapat dicapai melalui adanya peningkatan konten strategi yang dibangun oleh kualitas komunikasi.

Kebijakan yang berkaitan dengan variabel adaptabiltas adalah secara kontinu memonitoring perubahan lingkungan, hal tersebut dilakukan dengan cara menggali berbagai informasi yang relevan. Selanjutnya, kebijakan konten strategi adalah menyesuaikan sumber daya yang dimiliki dan konten strategi yang dibuat, jangan meniru konten strategi Bank Perkreditan Rakyat (BPR) lain, hal tersebut dikarenakan kekuatan dan kelemahan serta peluang dan ancaman berbeda. Kebijakan kelengkapan kajian adalah meningkatkan pengembangan tindakan alternatif, memanfaatkan peluang dengan analisis yang mendalam. Adapun kebijakan integrasi lintas fungsi adalah meningkatkan Keterlibatan (Level of cross functional involment) berkaitan dengan derajat koordinas, Kualitas (Quality cross functional informantion)berkaitan dengan ketepatan waktu dan informasi pada masing-masing bagian, dan c). Harmoni (Harmony of cross functional relations) berkaitan dengan derajat koordinasi pada aspek komunikasi, interaksi dan kerja sama masing-masing bagaian yang bertanggung jawab dan terjadi kepuasan dalam berinteraksi.

Kebijakan kapabilitas adalah meningkatkan pengembagan dan pelatihan secara kontinu dan sistematis. Hal tersebut dimaksudkan untuk meningkatkan pengetahuan, keterampilan dan pengalaman sumber daya manusia yang ada. Kebijakan komitmen adalah dengan meningkatan rasa memiliki organisasi (sense of belonging) dengan cara mendisstribusikan keterlibatan dalam berbagai kegiatan penting dalam organisasi. Akhirnya, kebijakan kualitas komunikasi adalah melakukan kegiatan informal dan tingkat manajerial yang lebih tinggi mengurangi dominasi dalam berkomunikasi

\section{PENUTUP}

Hasil pengujian full model SEM menunjukkan bahwa model tersebut sesuai dengan data atau fit terhadap data yang digunakan. Namun terdapat dua uji kesesuaian yang diterima secara marginal yakni Goodness of Fit Indeks (GFI= 0.82.6) dan Adjusted Goodness of Fit Indeks $(\mathrm{AGFI}=0.791)$.

Budaya organisasi merupakan pola yang terpadu perilaku manusia serta berkaitan dengan masalah penyesuaian atau integrasi kondisi internal dan eksternal. Berdasarkan hasil studi BPR Provinsi Jawa Tengah memiliki karakteristik yang berbeda jika dibandingkan dengan BPR Provinsi lain. Hal tersebut disebabkan sebagian besar BPR Provinsi Jawa Tengah dimiliki oleh pemerintah daerah baik pemerintah kabupaten/kota maupun pemerintah provinsi. Kepemilikan oleh pemerintah daerah perlu penanganan yang berbeda dengan BPR yang dimiliki oleh perseorangan atau swasta. Oleh karena itu budaya organisasi memiliki peran dalam proses pengembangan kualitas strategi dalam upaya meningkatan kinerja organisasi. Dengan demikian studi lanjutan budaya organisasi dalam proses pengembangan kualitas strategi, merupakan area studi yang menarik.

Di negara maju pemicu peningkatan kinerja organisasi pada umumnya dominan bersumber pada kondisi internal. Namun di negara berkembang kondisi eksternal (lingkungan) dominan berpengaruh pada peningkatan kinerja organisasi. Kondisi lingkungan mencakup Kompleksitas lingkungan merupakan keragaman faktor-faktor dan masalah-masalah yang ada di dalam lingkungan organisasi, dan dinamika lingkungan menggambarkan tingkat perubahan yang terjadi dalam lingkungan dimana organisasi beroperasi. Oleh karena itu agenda penelitian mendatang perlu dipertimbangkan. Khususnya kualitas implementasi strategi dan model kualitas evaluasi strategi karena studi ini sebagian besar lebih menekankan pada kondisi internal organisasi.

\section{DAFTAR PUSTAKA}

AL-Ma'ani, A.I. and N. Jaradat. 2010. Impact ff Human Capital on the Organization Performance. Interdisciplinary Journal of Contemporary Research in Business. 2 (4), 63-73. 
Andrews, R., G.A. Boyne, J. Law and R.M. Walker. 2009. Strategy Formulation. Strategy Content and Performance. Public Management Review. 11.

Andrews, R., Boyne, G.A. George and R.M. Walker. 2006. Strategy Content and Organizational Performance: An Em birical_Analysis Public Administration Review. 9.

Berberoğlu. A. and Ü. Emine. 2011. Relation Between Organizational Learning and Organizational Commitment: Case Studv of a Private Bank in North Cvprus. Proceedings of the European Conference on Intellectual Capital. 8793.

Bokor, D.W. and P.D. Olson. 1995. Strategy Process-Content Interaction: Effect on Growth Performance in Small Star-up Firms. Journal of Small Business Management. (33). 34-44.

Luquette, B.V. 1990. White Water, Still Water: Strategy Making Processes For Navigating A Changing Domain. Dissertation. Texas A \& M University.

Cohen. B.P. 1993. The significance of Human resources Management: A reconsideration of the evidence. International Journal of Human relation Management. 645-664.

Cook J and T. Wall. 1980. New work attitude measures of trust, organizational commitment and personal need nonfulfillment', Journal of Occupational Psychology. 53. 39-52.

Deborah S.N. and F. Damanpour. 2000. Organizational Complexity and Innovation: Development and Testing Multiple Contingency Models. Management Science. 39-716.

Deery. SP and R.D. Iverson. 2005. Labor Management Cooperation: Antecedesnts and Impact on Organizational, Performance. Industrial and Labor Relations Review. 58 (4). 588-609.

Dess.G.D., G.T. Lumpin and J.G. Covin. 1997. Entrepreneurial Strategy Making and Firm Performance: Test Contingency and Configurational Models. Strategic Management Journal. 677 - 689.

Denison. D.R. and A.K. Mishra. 1995. Toward a Theory Organizational Culture and Effectiveness. Organization Science. $204-223$.

Erdem, O., P. Sedat and S. Demirel. 2010. Characteristic of High Performance. Akdemir Bünyamin University. Journal of Faculty of Economics \& Administrative Sciences.15 (1). 155-174.

Ferdinand, A. 2000. Structural Equation Modelling Dalam Penelitian Manajemen. Semarang: BP Undip.

Ferdinand, A. 2002a. Kualitas Strategi Pemasaran Sebuah Studi Pendahuluan.' Jurnal Sain Pemasaran Indonesia. I (1). 107-119.

Ferdinand, A. 2002b. Marketing Strategy Making: Proses dan Agenda Penelitian.' Jurnal Sain Pemasaran Indonesia, I (1). 1- 22.

Ferri. G. and M. Messori. 2000. Bank-firm Relationships and Allocation Efficiency in North-Eastern and Central Italy and the South. Journal of Banking and Finance. 24. 1067-1095.

Forbes, D.P. 2007. Reconsidering the strategic Implications of Decision Comprehensiveness. Academy of Management Review. 32 (2). 361-376.

Bhattacharya, M., D.E. Gibson, C.F. Dolan and D.H. Doty. 2005. The Effects of Flexibility in Employee Skills, Employee Behaviors, and Human Resource Practices on Firm Performance. Journal of Management. 31(4). 1-19.

Gima.K.A and J.Y Murray. 2004. Antecedents and Outcomes of Marketing Strategy Comprehensives. Journal of Marketing. 63. 33-46.

Gozali, I. 2001. Logistic Regression dalam: Aplikasi Analisis Multivariat dengan program SPSS. Edisi 2. Semarang: Badan Penerbit Universitas Diponegoro. 120-130. 
Goebel, D.J., G. W. Marhall and W. B. Locander. 2004. An Organizational communication -based model of individual customer orientation of non Marketing members of firm. Journal of Strategic Marketing.11. 29-56.

Grant, R.M. 1991. The Resource-based Theory of Competitive Advantage: Implications for Strategy Formulation. California Management Review.33 (3).114.

Hair, J., B. Black, B. Babin, R. Anderson and R. Tatham. 2006. Multivariate Data Analysis. $6^{\text {th }}$ edition. Upper Saddle River, NJ: Prentice-Hall.

Han, J.K., N. Kim, R.K. Srivaastava. 1998. Market Orientation and Organizational Performance: Is Innovation a Missing Link ?. Journal of Marketing.62. 4553.

Johkle, M.C and G.R. Ferris. 2000. Social Context of Performance Evaluation Decisions. Academy of Management. 36 (1). 80-94.

Judge, A.T. and G.R. Doley. 2000. Human Resources Management and Performance: A Comparative Study of Ireland and the Neterlands. Management Revue.16(2). 242-257.

Kaleka, A. 2011. When Exporting Manufacturers Compete on the Basis of Service: Resources and Marketing Capabilities Driving Service Advantage and Pent formance. Journal of International Marketing. 19(1). 40-58.

Kohli, A. and K. Jaworski. 1990. Market Orientation "The Construct, Research Proportion and Managerial Implication. Journal of Marketing. 54 (April). 1-18.

Kulkarni, S.P. 2010. Sustaining the equality of employee voice: a dynamic capability. International Journal of Organizational Analysis. 18 (4). 442 - 465.

Levin, I., J.Z. Gottlieb. 2009. Realigning Organization Culture for Ontimal Performance: Six principles \& eight bractices. Organization Development Journal. 27 (4). 31-46.
Leonidou, L.C., D. Palihawadana and M. Theodosiou. 2011. National Export Promotion Programs as Drivers of Drganizational Resources and Canabill. ties: Effects on Strategy. Competitive Advantage and Performance. Journal of International Marketing. 19 (2).129, 29.

Locander, M. and J.C. Jaramillo. 2006. On Strategic Net Works. Strategic Management Journal. 9. 31-41.

Lowry, P. B., N.C. Romano Jr., J.L. Jenkins and R.W. Guthrie. 2009. The CMC Interactivity Model: How Interactivity Enhances Communication Ouality and Process Satisfaction in Lean-Media Groups. Journal of Management Information Systems. 26 (1). 155-195.

Mithas, S., N. Ramasubbu and V. Sambamurthy. 2011. How Information Management capability Influences Firm Performance. MIS Quarterly. 35 (1). 137-A15.

Menon, A., S.G. Bharadwaj, P.J. Adidam and S.W. Edison. 1999. Antecedents and Consequence of Marketing Strategy Making: Model and Tes. Journal of Marketing. 63. 18-40.

Michallisin.M.D, R.D. Smith and D.M. Kline. 1997. In Search of Strategic Assets. International Journal of Organizational Analysis. 360 -375.

Miller M.D and K. Michael. 1998. Five-Factor Model of Personality and performance in Jobs Involving Interpersonal Interactions. Human Performance. 145-165.

Miller, C.C. 2008. Decisional_comnrehensive hess and firm performance: towards a more complete understanding Journal of Behavioral Decision Making. 21(5). 598-620.

Mintzberg. H. 1990. The Design school: Reconsidering the Basic Premise of Strategic Management. Strategic Management Journal.11. 171-195.

Modwday, R.T. 1981. Viewing Turnover from The Perspective of Those Who Remain the Relationship of Job Attitude to 
Attribution of The Causes of Turn Over. Journal of Applied Psychology. 113-115.

Murray, S. and R.M. Castaldi. 1992. Antecedent and Propensity for Diversification: A focus Small Banks. Journal of Small Business Management. 42-56.

Parry, M.E., P.F. Ferrín, J.A.V. González. 2010. Persnective Cross-Functional Integration in Snanish Firms.; Song, Michael. Journal of Product Innovation Management. 27 (4). 606-615.

Pitt, L. F. and Kannemeyer. 2000. The Role of Adaptation in Microenterprise Development: a marketing perspective. Journal of Developmental Entrepreneurship. 5 (2). $123-135$.

Quinn. JJ. and S. Hart. 1993. Roles executives play: CEOs, behavior complexity, and firm performance. Human Relation. 46. 543-574.

Tery W. N. and S. B. Banerjee. 1999. Corporate Environment Strategies and Actions. Management Decision. 36-44.

Sengupta, S., R.E. Krapfel and M.A. Pusateri. 2000. An Empirical Investigation of Key Account Sales person effectiveness. Journal of Personal selling \& Sales Management. 253-261.

Sekaran, U. 2003. Research Methods for Business. A Skill Building Approach. USA: John Wiley \& Son.

Slotegraaf, R.J. and P.R. Dikson. 2004. The Paradox of a marketing Planning Capability. Academy of Marketing ScienceJournal .32. 373-385.

Song X.M, J. Hie dan B. Dyer. 2000. Antecedents and Consequence of Marketing Manager' Conflict-Handling Behaviors. Journal Marketing. 64 (January). 50-66.

Teece, D.J., G. Pisano and A. Shuen. 1997. Dynamic Capabilities and Strategic Management. Strategic Management Journal. 18 (7). 510-533.
Thomas, G. F., Z. Roxanne and J.L. Hartman. 2009. The Central Role of Communication in development trust and its effect on employee involvement. Journal of Business Communication. 46 (3). 287-310.

Troy, L. C., T. Hirunyawipada and A.K. Paswan. 2008. Cross-Functional Inte. gration and New Product Success: An Empirical Investigation of the Findings. Journal of Marketing. 72 (6). 132-146, 15.

Ulrich, L., W. Johnson and A. Richard. 1997. Modeling the Determinants of Customer Satisfaction for Business to Business Professional Service. Journal of The Academy of Marketing Science. 25 (1). 4-17.

Varadarajan, P.R. dan S. Jayachandran. 1999. Marketing Strategy: An Assessment of the State of the Field and Outlook. Journal of the Academy of Marketing Science 120 -143.

Walker, R.M. and G.A. Boyne. 2006. Strategy Content and Organizational Performance. An Empirical Analysis. Public Administration Review. 52-63.

Walker, O.C. and M.F. Neil. 1997. Motivation and Performance in Industrial Selling Present Knowledge and Needed Research. Journal of Marketing Research. 14. 156-168.

Weiss, L. and J.H. Hoffer. 2004. Coordination Network Within and Across Organization: A Multi - level Framework. Journal of Management Studies. 128-153.

Zeffane, R. S.A. Tipu and J.C. Ryan. 2011. Communication. Commitment and Trust: Exploring the Triad. International Journal of Business \& Management. 6 (6). 77-87

Zikmund, W. 2003. Business Research Methods. $6^{\text {th }}$ edition. Forth Worth: Dryden Press. 